\title{
ENHANCING PROGRESSIVE COLLPAPSE RESISTANCE OF RC BUILDING USING VISCOELASTIC DAMPERS
}

\author{
Parth D. Javia ${ }^{1}$, Digesh D. Joshi ${ }^{2}$, Paresh V. Patel ${ }^{3}$ \\ ${ }^{1}$ Post-graduate student, Civil Engineering Department, Institute of Technology, Nirma University, Ahmedabad \\ 382481, Gujarat, India \\ ${ }^{2}$ Assistant Professor, Civil Engineering Department, Institute of Technology, Nirma University, Ahmedabad 382481, \\ Gujarat,India \\ ${ }^{3}$ Professor, Civil Engineering Department, Institute of Technology, Nirma University, Ahmedabad 382481, Gujarat, \\ India.
}

\begin{abstract}
Progressive collapse denotes a failure of large part of the structure, causing greater damage to the structure than the initial impact, which has been initiated by failure of a relatively small part of the structure such as failure of any vertical load carrying elements (typically columns). Failure of large part of any structure will results into substantial loss of human lives and natural resources. Therefore, it is important to prevent progressive collapse which is also known as disproportionate collapse. Generally, viscoelastic dampers are used for improving performance of building during earthquakes. In the present study, effect of viscoelastic dampers on progressive collapse resistance of 4-storey Reinforced Concrete (RC) building is evaluated. Linear static and linear dynamic analysis are performed by following U. S. General Service Administration (GSA) guidelines for evaluating progressive collapse potential. Modelling and analysis is performed using SAP2000 for two different threat independent column removal scenarios. Demand Capacity Ratio (DCR) is calculated as suggested by GSA guidelines. From the analysis results, it is observed that viscoelastic dampers significantly reduces DRC for beams and columns as well as considerably reduces displacement at the location of removed column.
\end{abstract}

Keywords:Progressive Collapse, Viscoelastic Dampers, Linear Static Analysis, Linear Dynamic Analysis, Demand Capacity Ratio (DCR)

\section{INTRODUCTION}

Progressive collapse is a situation where local failure of a primary structural component leads to the collapse of adjoining members, which in turn leads to spread of collapse. It initiated when one or more vertical load carrying elements are seriously damaged or collapsed during any of the abnormal events. Once a local failure takes place, the building's gravity load transfers to neighboring elements of the structure. If these elements are not properly designed to resist and redistribute the additional load, that part of the structure also fails. As a result, a substantial part of the structure may collapse, causing greater damage to the structure than the initial impact. Thus it is necessary to provide sufficient redundancy, ductility and continuity, which helps the structure to find alternate paths for load distribution during undesired failure event and thus to reduce progressive collapse.

A number of potential abnormal load hazards, which could trigger progressive collapse areGas Explosions, Bomb explosion (Blast load), Design/Construction error, Fire, Overload due to occupant misuse, Vehicular collision, Aircraft Impact etc.Historical background of progressive collapse includes collapse of Alfred-Murrah building, Skyline plaza Collapse, World trade Centre collapse etc.After the collapse of World Trade Center Towers in September 2001, interest of structural engineers is increased in evaluating the progressive collapse potential for the buildings. Many guidelines are available for progressive collapse analysis and design of building structures, but among these guidelines, the U. S. General Service Administration (GSA) [1] and Unified Facilities Criteria (UFC 4-023-03) published by Department of Defense (DoD) [2] provides detailed step wise procedure and methodologies to resist the progressive collapse of building structures.Many structural Engineers and academic researchers have been engaged in the prevention of progressive collapse. Kim et al. [3] studied progressive collapse resisting capacity of structures with viscous dampers using nonlinear time-history analysis based on column removal scenario. Marjanishvili and Agnew [4] discussed comparison of different method of progressive collapse analysis of 9-storey steel moment resting frame. McKay et al. [5] assessed behaviour of a various RC and steel moment-frame buildings and evaluated dynamic load amplification factor. Many authors has evaluated progressive collapse potential of steel moment resisting frames [6-7]. Joshi and Patel [8] presented different approaches for progressive collapse mitigation of 4-storey and 10-storey RC building under different column removal scenario. 


\section{BUILDING CONFIGURATION}

In this study, progressive collapse potential of 4-storey building frame is evaluated. 2-D frame is considered for the study, which is extracted from building having overall plan dimensions $10 \mathrm{~m} \times 20 \mathrm{~m}$ as shown in Fig-1, by transferring forces of slabs on beams. The frame is having 4 bays at $5 \mathrm{~m} \mathrm{c} / \mathrm{c}$ spacing as shown in Fig-2. Total height of the frame is $12.7 \mathrm{~m}$ having the first storey height as $3.4 \mathrm{~m}$ and height at all other storey is $3.1 \mathrm{~m}$. Typical elevation of the 4-storey frame considered for the study is shown in the Fig-2. Walls of 115 $\mathrm{mm}$ thickness are considered on all the beams. Frame is analysed and designed by considering seismic forces. Modelling, analysis and design is carried out using SAP2000 [9]. Progressive collapse potential of building is evaluated for two different column removal scenarios i.e. middle column and internal column, as shown in Fig-1.

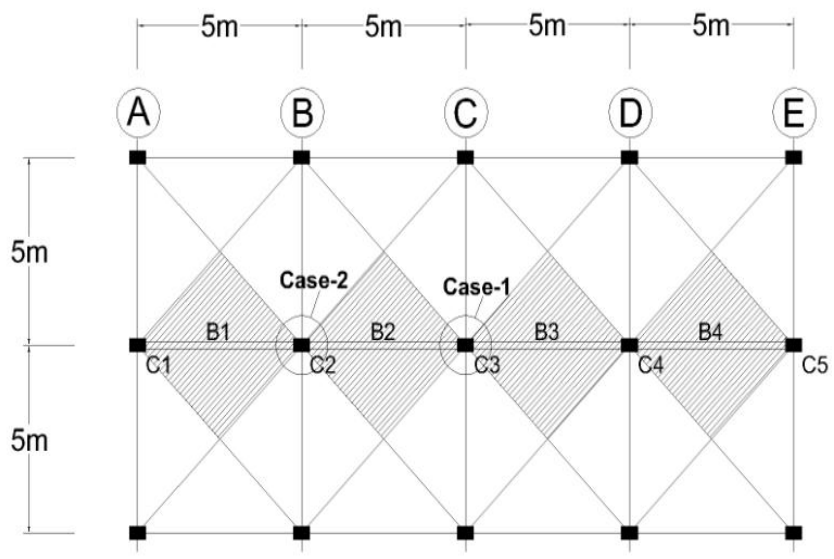

Fig-1: Plan of Building

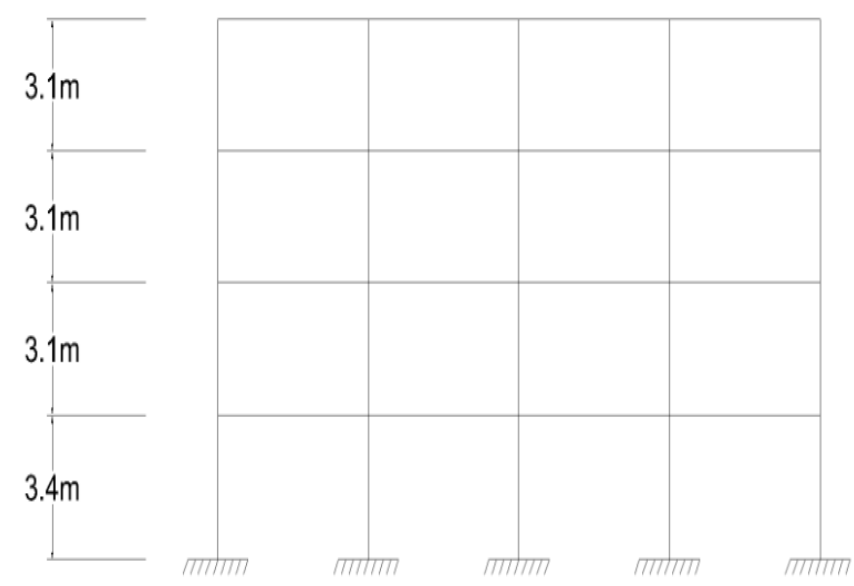

Fig-2:Elevation of Building

\section{PROGRESSIVE COLLAPSE ANALYSIS}

After designing 2-D frame, the vertical members as shown in Fig-1 are removed separately from bottom storey level. These two case has been considered which is based on exterior and interior column removal conditions, as suggested by U. S. General Services Administration (GSA) [1] and Unified Facilities Criteria (UFC 4-023-03) published by Department of Defense (DoD) [2] guidelines.

\subsection{Linear Static Analysis}

In linear static analysis column is removed from the location being considered and analysis is carried out for vertical load2 (DL + 0.25LL) which shall be applied downward on the structure. Where DL $=$ Dead load and LL $=$ Live load.To consider the dynamic effects, dynamic amplification factor 2 is considered in linear analysis, as suggested by guidelines. The Demand Capacity Ratio (DCR) is calculated at eachstorey for linear static analysis. DCR is calculated at three points left, center and right side of the column removal position. $\mathrm{L}, \mathrm{C}$ and $\mathrm{R}$ indicates the value of DCR at left, center and right side from the position of removed column respectively for linear static analysis. According to the guidelines structural elements having Demand Capacity Ratio (DCR) values exceeding 2.0 for flexure and 1.0 for shearare considered as severely damaged or collapsed.

\section{2linear Dynamic Analysis}

Linear dynamic analysis method involves real-time removal of load carrying structural elements (real-time removal of column). Thus it is more appropriate to refer to this method of analysis as a time history analysis. Here, in time history analysis, the frame is assumed to be at rest in its original configuration, and then subjected to a sudden column removal. To perform linear dynamic analysis the dynamic amplification factor of 2.0, used in the static analysis, is not considered because dynamic effect is already considered in analysis.In the linear dynamic procedure the load applied is half of that applied in the static procedure. This difference in load application is for the reason that the dynamic effects are already considered in the time history analysis.

A reaction is applied at the location of column removal as shown in Fig-3 and is make to zero after some elapsed time to incorporate dynamic effect using RAMPDOWN function. To simulate the dynamic effect of column removal, reaction is applied at column removal location and the time history function is definrd for the analysis as RAMPDOWN, at time $\mathrm{t}=0, \mathrm{f}(\mathrm{t})=1$ and at $\mathrm{t}=0.002, \mathrm{f}(\mathrm{t})=0$, also at time $\mathrm{t}=1, \mathrm{f}(\mathrm{t})=0$. Time history for gravity load is defined as $\mathrm{TH}$, at time $\mathrm{t}=0$, $\mathrm{f}(\mathrm{t})=1$ and at $\mathrm{t}=0.002, \mathrm{f}(\mathrm{t})=1$, also at time $\mathrm{t}=1, \mathrm{f}(\mathrm{t})=1$ which remains constant throught the analysis. Time histroy function definition in SAP2000 for linear dynamic analysis is shown in Fig-4.

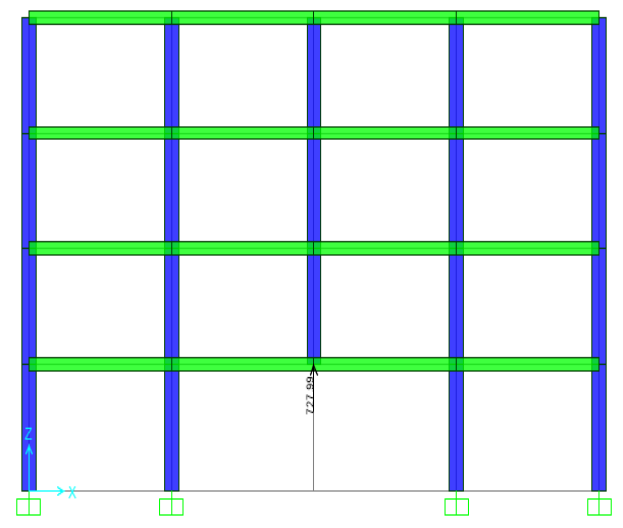

Fig-3:Reaction at column removal location 


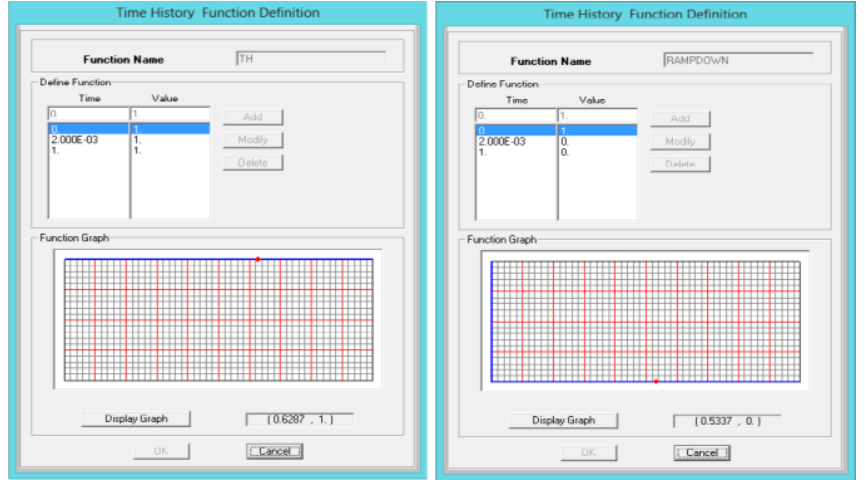

Fig-4: Time history function definition in SAP2000 for linear dynamic analysis

\section{DESIGN OF VISOELASTIC DAMPER}

Viscoelastic dampers are provided in central bays above the location ofremoved column as shown in Fig-5. Here, initially the required structural damping ratio $\xi$ is assumed. The design of viscoelastic dampers is carried out according to Kelvin Model [10]. Modelling of viscoelastic dampers is carried out using software SAP2000 [9]. Various parameters used for modelling of viscoelastic dampers are shown in Fig-6.

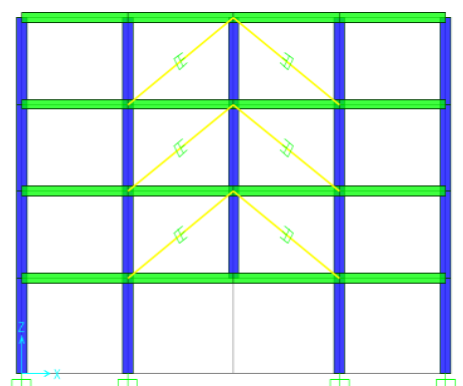

Fig-5:Viscoelastic elastic damper configuration

Procedure for design of viscoelastic damper for damping ratio $\xi$ equals to $20 \%$ is discussed below.

\section{Data considered:}

Fundamental frequency of the building $\omega=11.54 \mathrm{rad} / \mathrm{sec}$

Inherent Damping ratio of the building $=5$

Operating Temperature $\mathrm{T}=25^{\circ} \mathrm{C}$

Storey Height $\mathrm{h}=3.4 \mathrm{~m}$

Assumed Damping Ratio $\xi=20 \%$

Angle between bracing member and floor $\theta=30.96^{\circ}$

Target Added damping ratio $=15 \%$

From modal strain energy method,

$K d=\frac{2 \times \beta}{\eta-2 \times \beta} \times K s$

Where,

$\mathrm{Ks}=$ Storey stiffness

$\beta=$ Target Added damping ratio

$\eta=$ Loss factor $\left(G^{\prime} / G^{\prime}\right)$

$\mathrm{Kd}=$ Damper stiffness

G" = Shear loss modulus

$\mathrm{G}=$ Shear storage
Simplified relationship for shear storage $\left(G^{\prime}\right)$ and shear loss modulus (G”) is given by;

$\mathrm{G}^{\prime}=16 \times \omega^{0.15} \times \gamma^{-0.23} \times \mathrm{e}^{(72.46 / \mathrm{T})}$ and

$\mathrm{G}^{\prime \prime}=18.5 \times \omega^{0.15} \times \gamma^{-0.20} \times \mathrm{e}^{(73.89 / \mathrm{T})}$

If the maximum design damper strain $(\gamma)$ of $60 \%$ is assumed, then the damper thickness $(\mathrm{t})$ is;

$t=\frac{0.004 \times h \times \cos \theta}{\gamma}$

Where,

$\mathrm{h}=$ storey height

$\theta=$ angle of inclination of viscoelastic damper

Area of viscoelastic damper is calculated using following equation;

$A=\frac{K d \times t}{G^{\prime}}$

From area of viscoelastic damper, coefficient of damping $\mathrm{Cd}$ is calculated using equation;

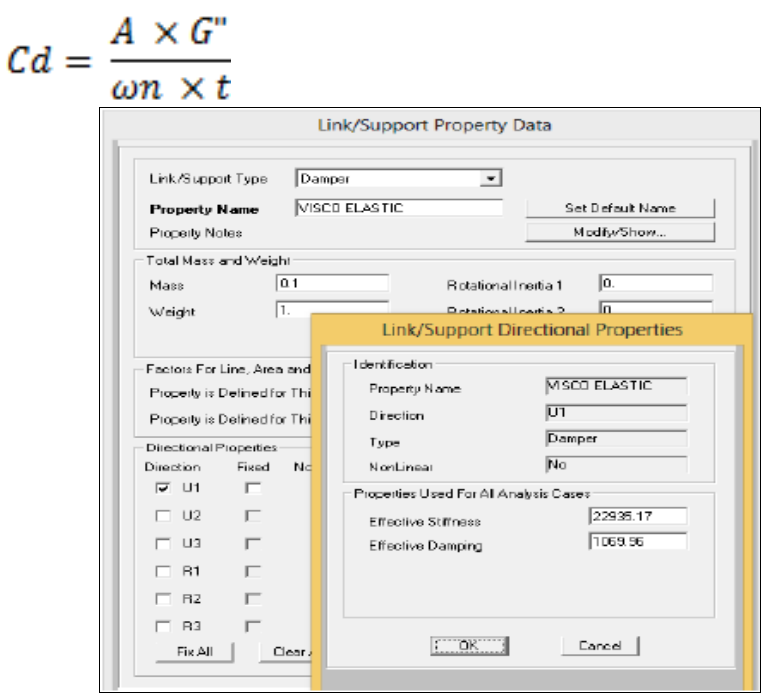

Fig-6:Input parameters for viscoelastic dampers

\section{RESULTS AND DISCUSSION}

DCR for flexure, DCR for shear and DCR for column is calculated at all the four stories for frame with damper and without damper and their results are compared.From analysis results of DCR for flexure as shown in Fig-7 to Fig10 , it is observed that DCR in beams of buildings without dampers are exceeding the allowable limit of 2 for both column removal scenarios, which indicates high potential of progressive collapse. When viscoelastic dampers are used, DCR for beams reduces significantly, which indicates enhanced progressive collapse resistance of building.From the results of DCR for shear as shown in Fig-11 to Fig-14 and results of DCR for column as shown in Fig-15 to Fig18, similar behavior is observed that, provision of viscoelastic dampers significantly reduces DCR values and brings it within the allowable limits of 1 . 


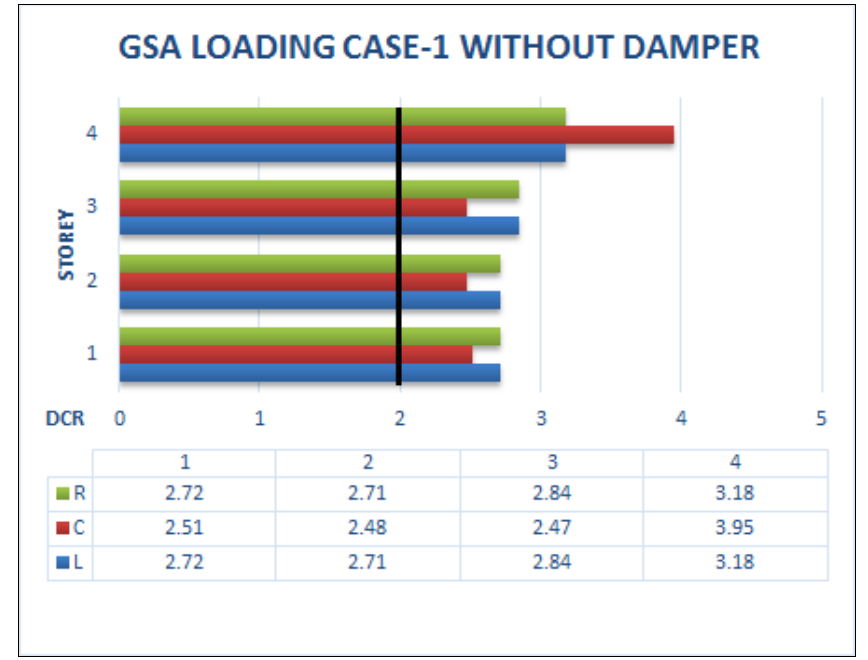

Fig-7:DCR for flexure for case-1 without dampers

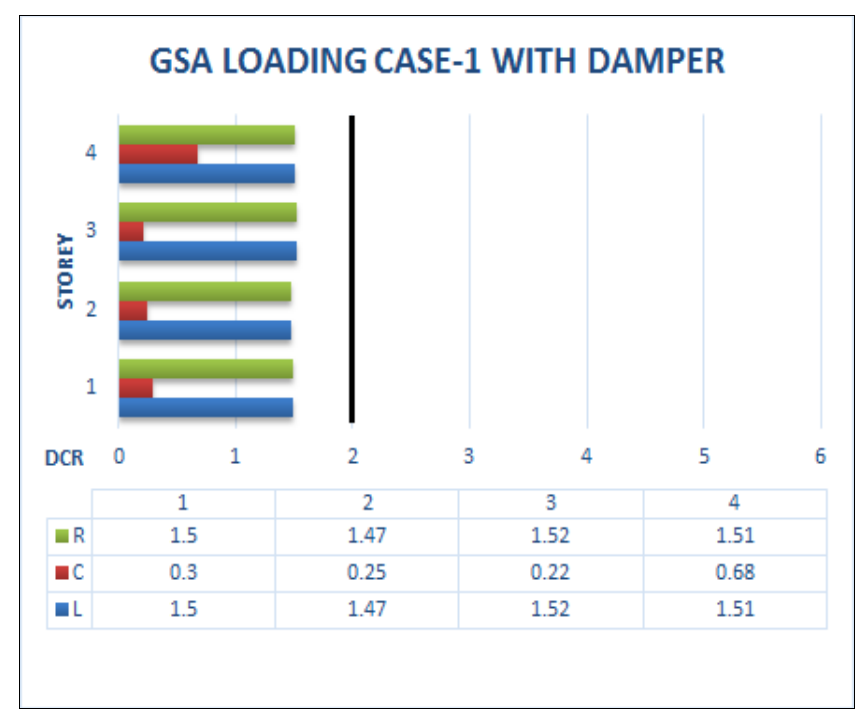

Fig-8:DCR for flexure for case-1 with damper

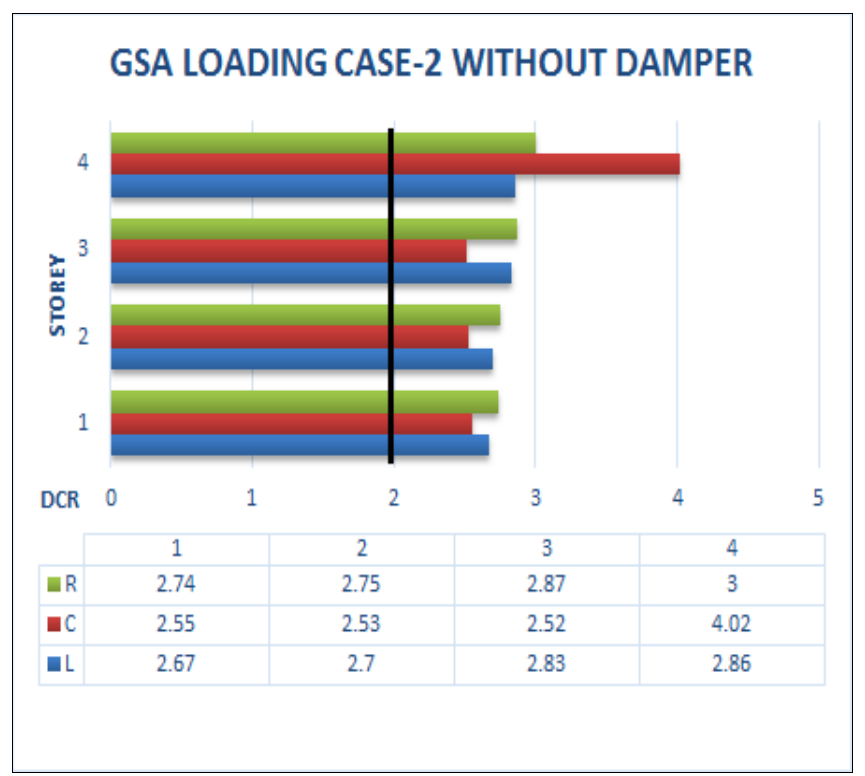

Fig-9:DCR for flexure for case-2 without damper

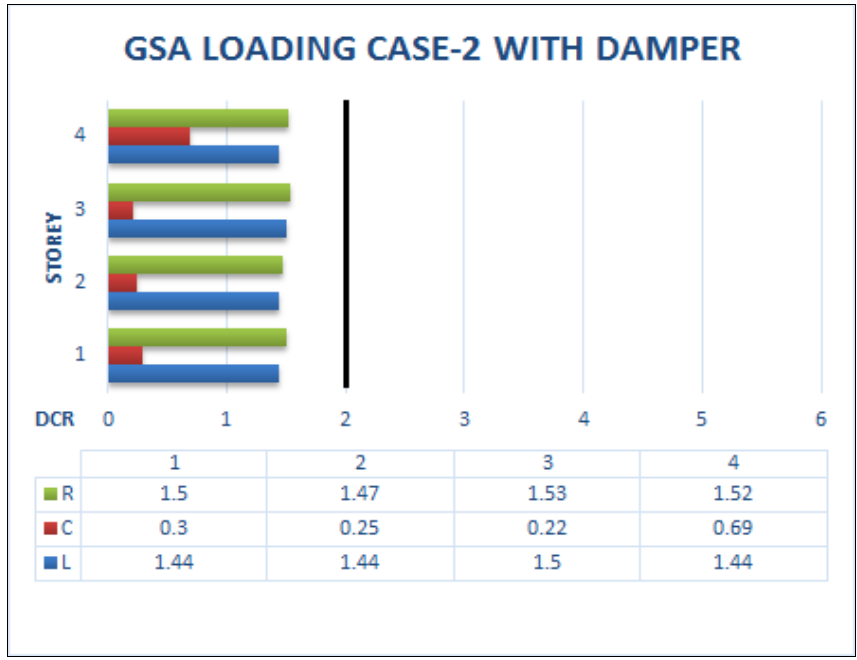

Fig-10:DCR for flexure for case-2 with damper

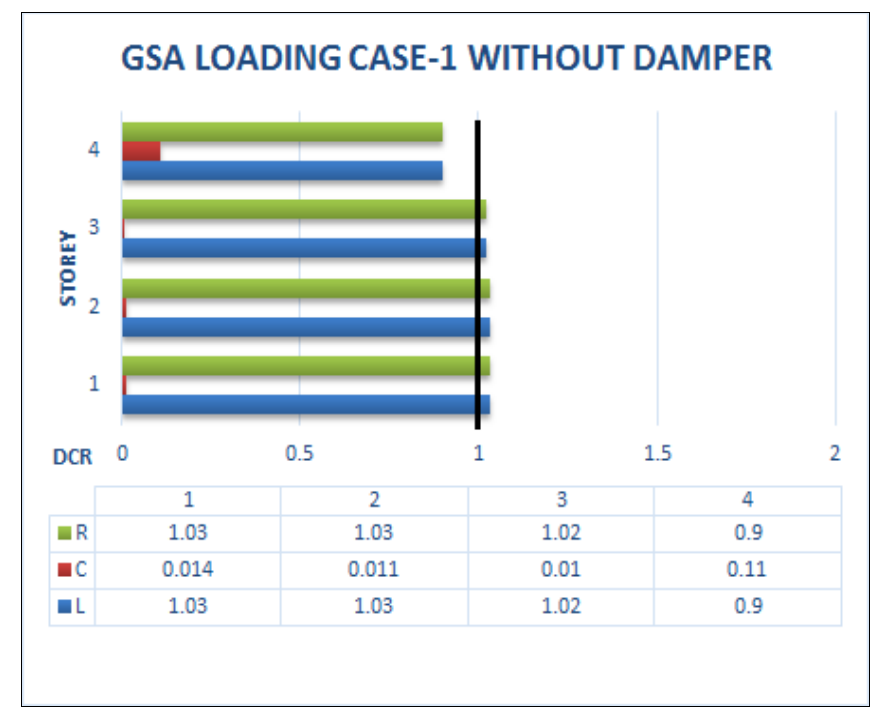

Fig-11:DCR for shear for case-1 without damper

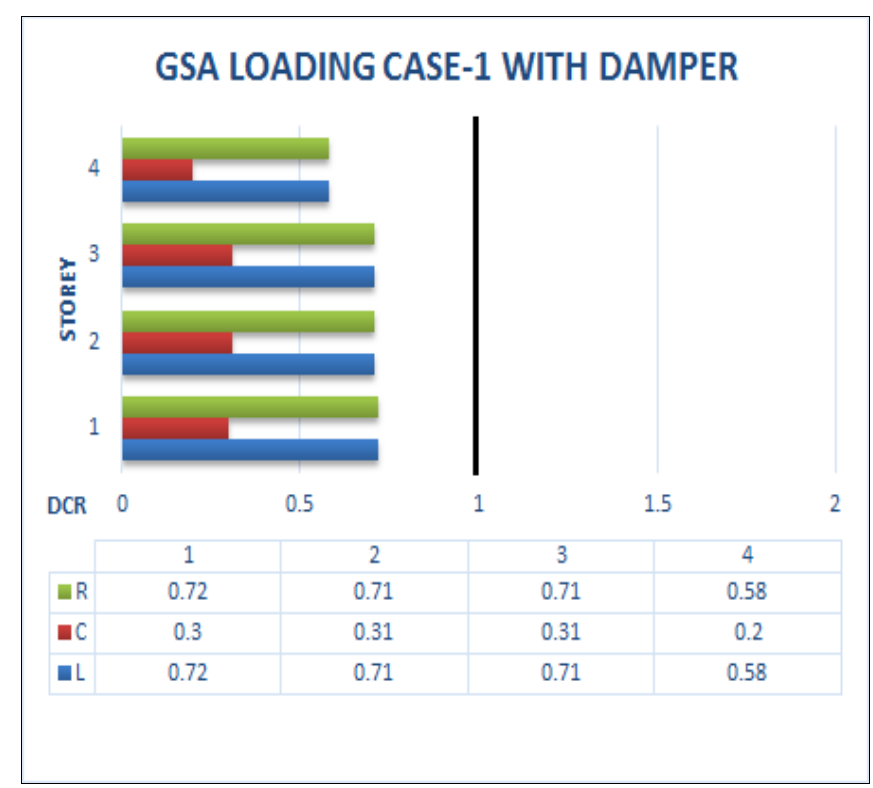

Fig-12:DCR for shear for case-1 with damper 


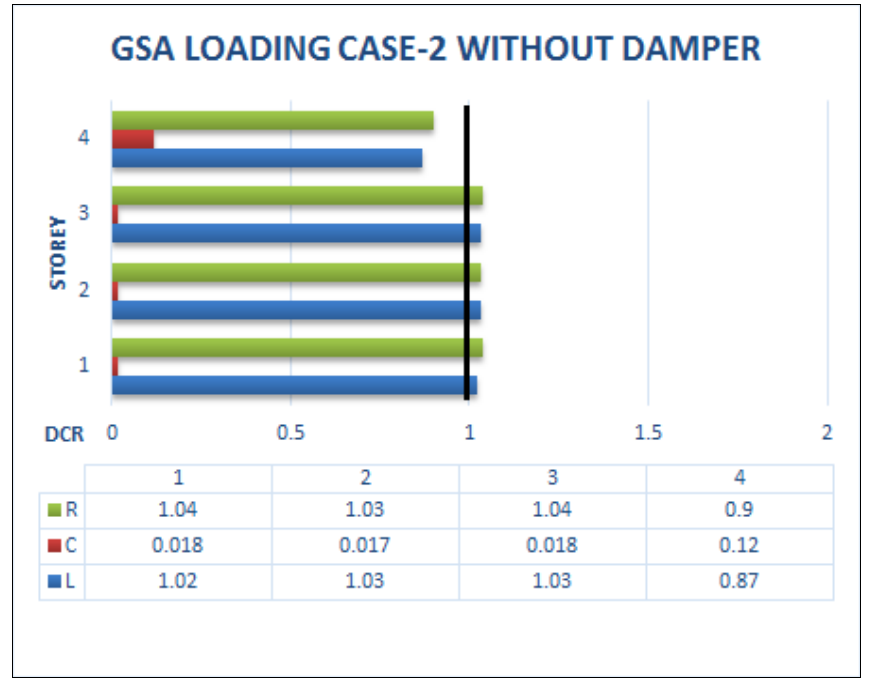

Fig-13:DCR for shear for case-2 without damper

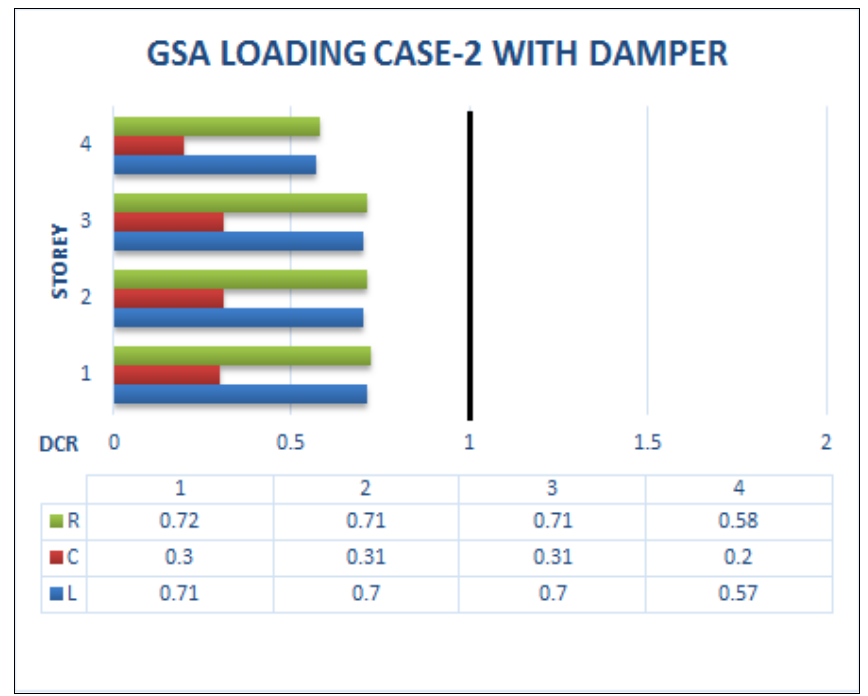

Fig-14:DCR for shear for case-2 with damper

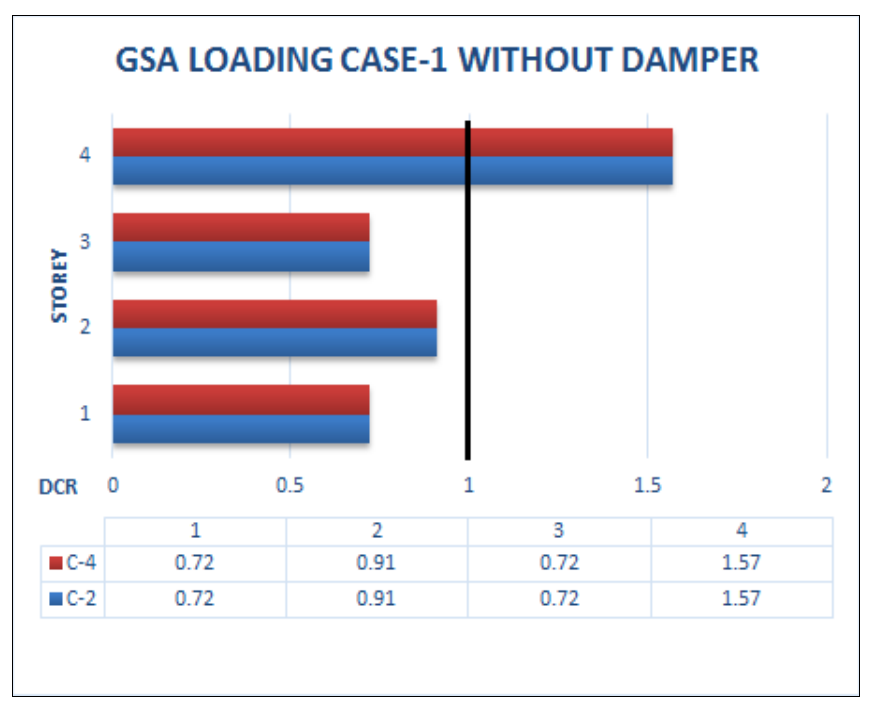

Fig-15:DCR for column for case-1 without damper

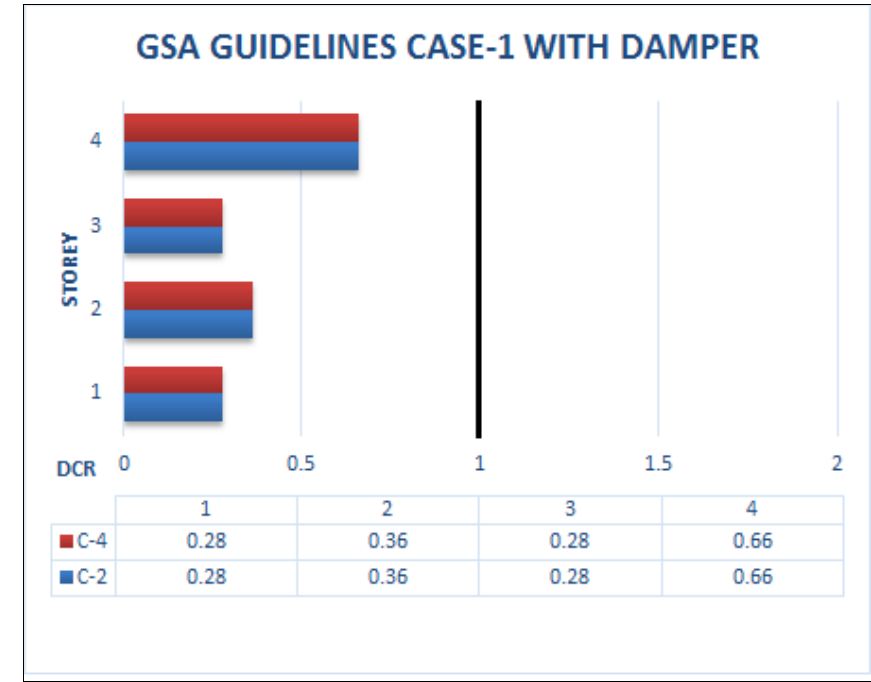

Fig-16:DCR for column for case-1 with damper

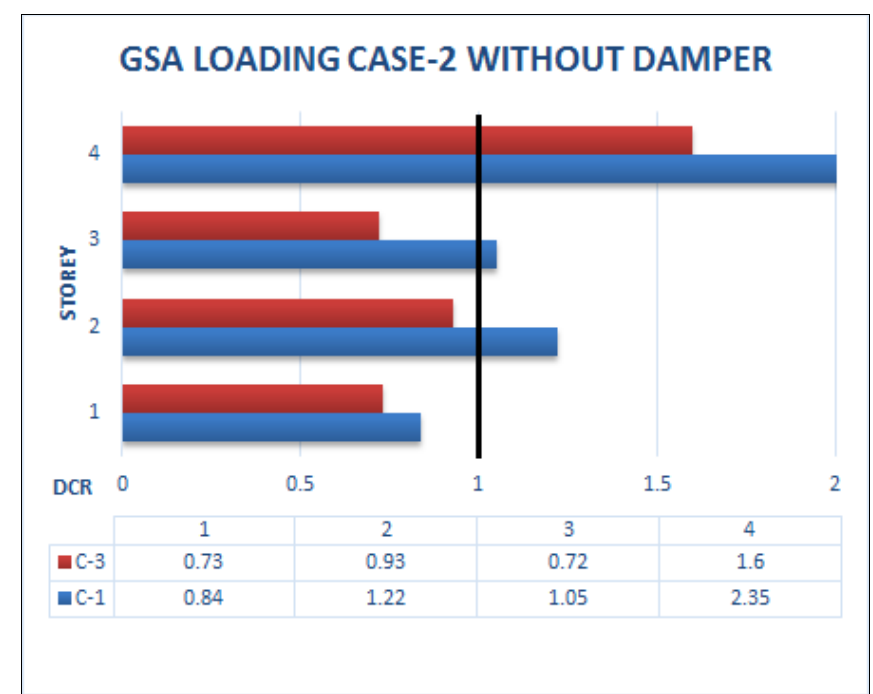

Fig-17:DCR for column for case-2 without damper

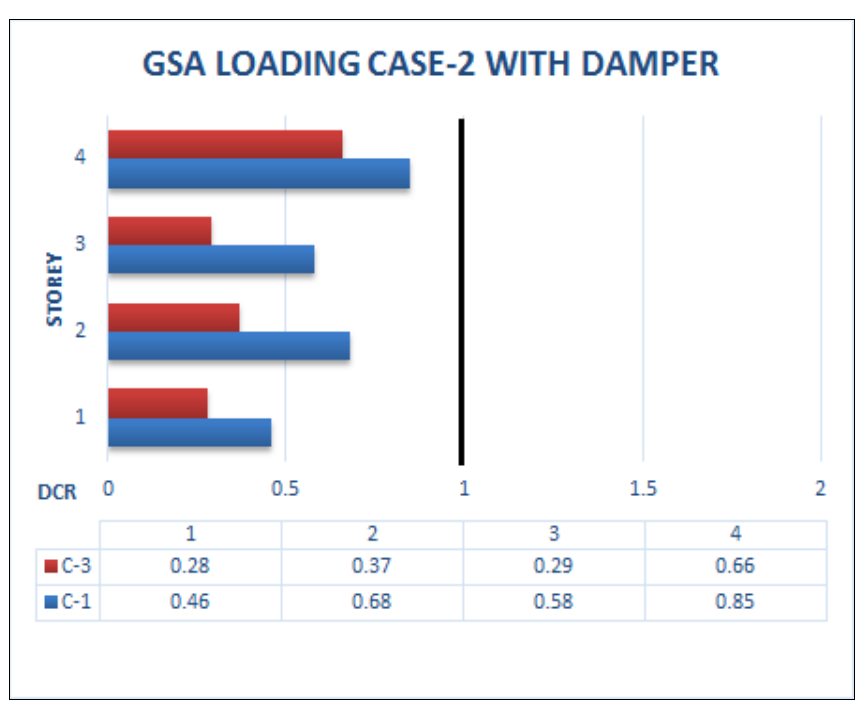

Fig-18:DCR for column for case-2 with damper 
Linear dynamic analysis is performed to obtain displacement at location of removed columns. Displacement at the location of column removal is maximum in case of frame without dampers and it is observed that after incorporating viscoelastic damper with suitable damping there is considerable reduction in the displacement at the location of removed column. As percentage of damping increases, the deflection of the column is decreases which is evident from the Fig. 19.

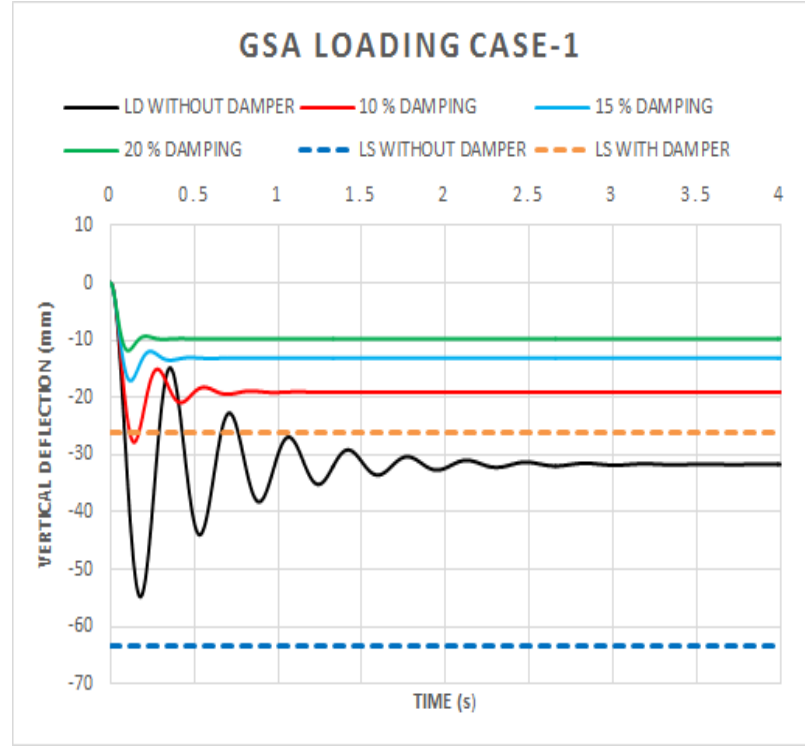

(a)

\section{GSA LOADING CASE-2}

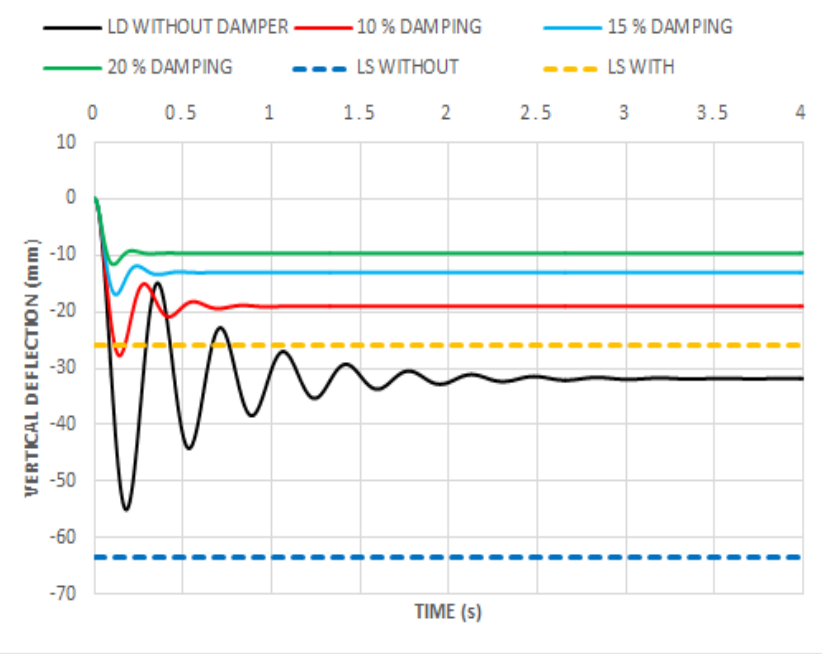

(b)

Fig-19:Deflection for column removal (a) case-1 and (b) case-2

The vertical deflection measured at the location of column removal for both the column removal cases is presented Table-1. Vertical deflection is maximum for linear static analysis as compared to linear dynamic analysis. Incorporating viscoelastic damper with suitable damping, considerably reduces the displacement at the location of removed column.
Table-1: Comparison of Vertical Deflection

\begin{tabular}{|l|l|l|l|l|}
\hline \multicolumn{5}{|l|}{ Maximum Vertical Deflection (mm) } \\
\hline Column & Linear & Linear & Linear & Linear \\
Removal & Static & Dynamic & Static & Dynamic \\
Case & Analysis & Analysis & Analysis & Analysis \\
& Without & Without & With & with \\
& Damper & Damper & Damper & Damper \\
\hline Case-1 & 63.30 & 54.77 & 26.13 & 11.77 \\
\hline Case-2 & 63.36 & 55.01 & 26.00 & 11.61 \\
\hline
\end{tabular}

\section{CONCLUSIONS}

Based on analysis results presented in this paper, following conclusions can be drawn.

- DCR for flexure in beams exceeds the permissible value 2 for both column removal cases i.e. middle column removal and interior column removal. Also, DCR for shear and DCR for column exceeds permissible value 1 for both the column removal cases which indicates high potential of progressive collapse.

- When viscoelastic dampers are used, DCR for beams as well as columns reduces significantly at all the floor levels and are within the permissible limits as suggested by GSA guidelines.

- Deflection at the location of column removal is maximum in case of frame without dampers. Incorporation of viscoelastic damper with suitable damping, considerably reduces the deflection up to $50 \%-70 \%$ at the location of removed column.

- The dynamic amplification factor of 2 is a good estimate for static analysis procedure, since linear static analysis and linear dynamic analysis produces almost similar maximum deflections.

\section{REFERENCES}

[1]. GSA,"Progressivecollapse analysisanddesignguidelines fornewfederalofficebuildingsandmajormodernizationpr ojects",TheU.S.GeneralServiceAdministration:Washin gtonDC; 2003.

[2]. DoD, "Design of Buildings to Resist Progressive Collapse", Unified facilities CriteriaDepartmentofDefense:Washington DC;2005.

[3]. Kim. J, Lee. S, Choi. H. Progressive collapse resisting capacity of moment frames with viscous dampers. The structural design of tall and special buildings, 2011, 4, Jan.2011.

[4]. S. Marjanishvili and E. Agnew. Comparison of Various Procedures for Progressive Collapse Analysis. Journal of Performance of Constructed Facilities, Nov 1:Vol. 20(2006); pp. 365-374.

[5]. McKay, K. Marchand, and M. Diaz. Alternate Path Method in Progressive Collapse Analysis Variation of Dynamic and Nonlinear Load Increase Factors. Practice periodical on structure design and construction. Vol. 17(2012); pp. 152-160.

[6]. J. Kim and T. Kim. Assessment of progressive collapse-resisting capacity of steel moment frames. Journal of Constructional Steel Research. Vol. 65(2009); pp. 169-179. 
[7]. R. Tavakoli, R. Alashti. Evaluation of progressive collapse potential of multi-story moment resisting steel frame buildings under lateral loading. Scientia Iranica, Vol .20 (2013); pp. 77-86.

[8]. P. Patel and D. Joshi. Various Approaches for Mitigating Progressive Collapse of Asymmetrical RC Building. Structures Congress 2012; pp. 2084-2094.

[9]. SAP2000 Version 15.0.Linear and nonlinear static and dynamic analysis and design of three-dimensional structures. Berkeley (CA, USA) Computers and Structures, 2007.

[10]. Robert D. Hanson and T. T. Soong, Seismic Design with Supplementary Energy Dissipation Devices, Monograph series, EERI, 2001.

\section{BIOGRAPHIES}

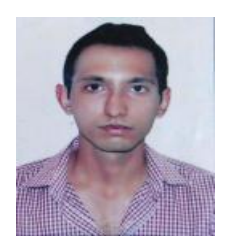

Mr. Parth D. Javia has done his M. Tech in Civil Engineering with specialization in Computer Aided Structural Analysis \& Design (CASAD) from Civil Engineering Department, Institute of Technology, Nirma University.

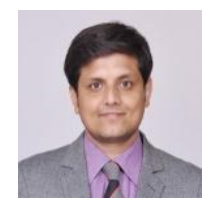

Prof. Digesh D. Joshi is working as an Assistant Professor in Civil Engineering Department of Institute of Technology, Nirma University. He is having 05 years of teaching experience

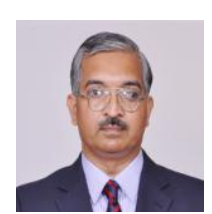

Dr. Paresh V. Patel is working as Professor \& Head of Civil Engineering Department, Institute of Technology, Nirma University. $\mathrm{He}$ is having 04 years of professional experience and 19 years of academic experience of teaching at UG and PG level 